\title{
Erratum zu: Exkurse
}

\section{Erratum zu: \\ Kapitel 9 : D. Frey et al., Mit Erfolg zur Professur oder Dozentur, https://doi.org/10.1007/978-3-662-60529-5_9}

Auf Seite 134 wurde die Referenz auf Abbildung 9.2 entfernt. Auf Seite 140 wurde die Referenz auf Abbildung 9.3 zu 9.2 korrigiert. Auf Seite 147 wurde die Referenz auf Abbildung 9.4 zu 9.3 korrigiert. Auf Seite 149 wurde die Referenz auf Abbildung 9.5 zu 9.4 korrigiert. Auf Seite 152 wurde die Referenz auf Abbildung 9.6 zu 9.5 korrigiert. 